\title{
Interorganisational networks and the diffusion process: The case of networks not working
}

\author{
M. Robertson, J. Swan, S. Newell \\ University of Warwick Business School, Coventry, CV4 7AL,UK \\ Fax: 441203 524965.E-Mail:wbsrbmr@wbs.warwick.ac.uk
}

\begin{abstract}
This research considers the diffusion of CAPM (Computer Aided Production Management) technology in the UK automotive sector, during the mid to late 1980's. The focus is on the role of interorganisational networks in the diffusion process. Previous research has recognised that potential adopters of CAPM technology are subjected to a pro-innovation bias when developing an awareness of the technology, such that adoption is considered always to be the best policy. Using three case companies where adoption of a variant of CAPM known as MRPII (Manufacturing Resource Planning) occurred, the decision making process leading to this investment is explored. Attention is given to the perceived influence of a variety of interorganisational networks on the decision making process.

Whilst, it is acknowledged that suppliers of CAPM technology (hardware and software vendors, management consultants) will support the pro-innovation bias, evidence is also presented here to suggest that a number of other interorganisational networks (including professional associations and academic institutions), reinforce this bias. Causal relationships cannot be inferred from this small number of cases. However, two factors are found to contribute to more positive outcomes, across the companies studied. These are substantial boundary spanning activity, particularly through the use of weak ties, coupled with access to a range of different interorganisational networks.
\end{abstract}

Keywords

Interorganisational networks, MRPII, production management, consultants

\section{INTRODUCTION}

This paper is based on case study data gathered from three manufacturing companies operating in the automotive sector in the UK. All three firms invested in a form of CAPM technology known as MRPII, during the late 1980's. The aim of the research was to examine the decision making process surrounding this investment. Specifically, examining the role played by a number of different interorganisational networks which provided potential adopters with an awareness of CAPM solutions.

CAPM technology consists of software based systems and operating procedures that plan and control inventory levels, material flows and the manufacturing operation. The technology 
aims to ensure that specified products are produced by defined methods to agreed dates within a context whereby the firms assets are utilised optimally. In an integrated form, this technology can support many different functions which draw upon information held on a common database to support their activities. During the 1980's there were three major variants of CAPM technology, MRPII (Manufacturing Resource Planning), JIT (Just-in-Time) and OPT (Optimal Production Technology) (Clark et al, 1992). MRPII technology is considered to be a highly centralised 'push' system of planning and control, pushing materials through the manufacturing operation. It requires organisations to adopt more integrated approaches to work organisation and practices. MRPII technology contrasts with JIT technology. JIT 'pulls' components from one work station to the next during the manufacturing operation, only when the downstream workstation requires them. OPT technology operates by identifying bottlenecks within the manufacturing operation. These three variants of CAPM were considered to be competing, rather than complementary technologies during the late 1980's.

The diffusion of MRPII technology is an interesting area to research. Failure rates, in terms of failure to successfully appropriate the technology, have been found to be as high as $70 \%$ in the UK and US (Krupp, 1984, Wilson et. al, 1994). The term 'appropriate' rather than adopt is used here. This form of technology is a multi-faceted, complex 'bundle' of technology rather than a single entity or 'technical fix'. It incorporates both technical and organisational features. It requires specific configuration within individual organisations subject to unique organisational context (Clark, 1987). With respect to MRPII technology then, it is not sufficient to only invest in software, education and training. Attention needs also to be given to the psychological and social construction of organisational and technical systems for MRPII to be successfully appropriated (Pinch \& Bijker, 1989).

Adoption of MRPII technology represents a significant capital investment. The software alone can cost anything within the region of $£ 30 \mathrm{~K}$ to $£ 1 \mathrm{M}$. In order for MRPII concepts to be applied, significant investment must also be made in education and training. Many organisations rely on software suppliers to provide some basic education and training. However, others use specialist consultants throughout the period of implementation (usually 18 months to 2 years). This also represents a further considerable financial investment. Where organisations fail to successfully appropriate the technology, not only do they incur significant capital loss, but the operating environment will have been severely impaired for the duration of the unsuccessful implementation phase.

Organisations were, to a limited degree, aware of the problems and failure rates associated with this technology (Waterlot \& Marriot, 1986). However, research found that potential adopters of the technology were subject to a pro-innovation bias. That is, when developing an awareness of the technology, adoption was always considered to be the best policy. Ultimately then, large sections of UK manufacturing industry invested in MRPII technology (NEDO, 1984). Previous research suggested that this pro-innovation bias was largely generated by software vendors and management consultants with a vested interest in promoting MRPII technology (Clark \& Staunton, 1989). Further research highlighted professional associations also supporting the pro-innovation bias (Swan J. \& Newell, S, 1995). The research found that the developers of the first MRPII software packages, IBM, used The American Production \& Inventory Control Society (APICS) as an effective channel through which to diffuse information about their product and the technology generally. The company was able to do this by the active participation of IBM consultants within Chapters of the of the Association across the US and North America. This association has licensee agreements with other associations in many countries throughout the world. Licensees receive much of their information from APICS. Thus the research found that this pro-innovation bias generated by APICS subsequently diffused to practitioners in the UK, through the British Production and 
Inventory Control Society (BPICS). It is acknowledged that professional associations are important in the diffusion process as they provide crucial links across networks, so that contact is made between practitioners in industry and individuals in other sectors, such as suppliers, academics, research institutes etc. However, BPICS diffused American ideas about 'best practice' which heavily promoted the use of MRPII technology, to the exclusion of other technologies and therefore provided information that was incomplete, irrelevant or redundant.

This current research extends this analysis. It considers the influence of a range of interorganisational networks on the diffusion of MRPII technology, to try and more fully understand how potential adopters develop an awareness of MRPII.

\section{INTERORGANISATIONAL NETWORKS}

The concept of inter-organisational networks is problematic in that definitions abound. It is necessary therefore to be clear about how the term 'network' is to be used here. Networks constitute the basic social form that permits interorganisational interactions of exchange (including the exchange of knowledge) between unbounded or bounded groups of organisations (Alter \& Hage, 1993). Organisations engage in information exchange and collection in order to reduce uncertainty and networks provide the necessary vector for informational flow. This definition is supported by the industrial network perspective which focuses on the 'space' between organisations (Axelsson \& Easton, 1992). Recognising that "there are a number of types of relationship in a network where direct economic exchange is absent though other forms of relationship (primarily informational) may exist, e.g. between competitors" (Axelsson \& Easton, 1992:12).

These definitions then are useful in recognising that employees within organisations are involved in a set of exchange relations, which includes the exchange of knowledge and expertise, with other social actors, both within and across industrial sectors. Through the activity of such employees, organisations are more likely to learn about new technologies and consequently make more informed adopt/reject decisions.

Employees involved in this type of activity are defined as 'boundary spanners'(Tushman \& Scanlan, 1981). Boundary spanning may be formal or informal. The latter being characterised by the importance and strength of weak ties within and between interorganisational networks (Granovetter, 1973). It is this boundary spanning activity and its influence on the early stages of the diffusion process which forms the basis of this research.

\section{INNOVATION DIFFUSION THEORIES}

The dominant sociological theorist regarding the diffusion of innovations was Rogers (1962, 1983) - see Clark \& Staunton (1989). Rogers second framework consists of five distinct phases described in a sequential manner (knowledge, persuasion, decision, implementation, institutionalising). This framework is useful in that it acknowledged that prior to the decision to adopt (or reject) an innovation, potential adopters are involved in a process of persuasion. The organisation is exposed to a variety of sources of information regarding the innovation, through the activities of boundary spanners - technological gatekeepers, who influence the adopt/reject decision. Importantly, the model highlights the role of suppliers in making potential adopters aware. Thus, the suppliers are shown as active boundary spanners, whilst potential adopters are taken to be relatively passive.

Roger's framework also recognises that there may be a requirement to modify and reconfigure the innovation to make it suitable for a specific organisational context. This is referred to by Rogers as the institutionalising stage. This is particularly relevant to the appropriation of MRPII technology. MRPII technology is classified as a configurational 
technology. A technology that requires contextual embedding within the adopting organisation, in order to be used optimally (Fleck, 1993).

There are drawbacks however, when attempting to apply Rogers' framework to this research. The diffusion process is described as a simple, linear, sequential process, driven by the needs of potential adopters. It does not adequately address the dynamics of the relationship between suppliers and adopters and the active participation of potential adopters in the diffusion process.

For the purposes of this research then, the Decision Episode Framework (DEF) is more relevant. The DEF was initially proposed by Clark \& Staunton (1989), and later developed by (Newell, Swan \& Clark (1993). The DEF (shown in Figure 1) does focus on the needs and activities of potential adopters.

Figure 1: The Decision-Episode Framework:The context for user decisions (adapted from Clark et al 1992)

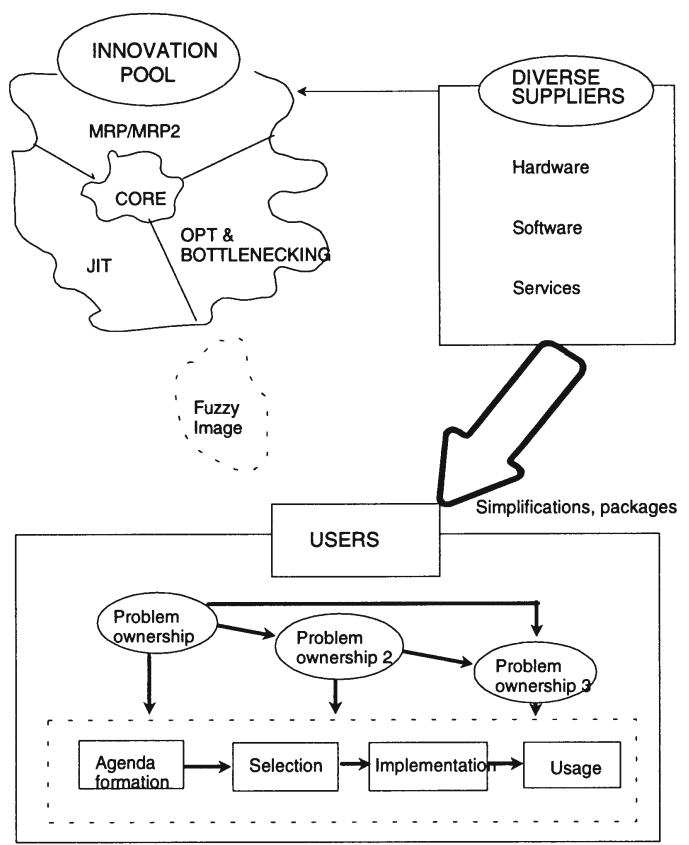

The DEF is an attempt to contextualise both the decision making process and the problems faced by potential adopters when designing CAPM solutions. The framework consists of three interacting elements; the innovation pool; the supply side; and the users. The innovation pool comprises the major variants of CAPM technology with an overlapping core. This illustrates the commonality across the three technologies. The commercial supply side is said to shape availability of the technology to the users and consists of a diverse set of hardware, software and consultancy service vendors, all presenting a favourable and simplified version of the particular technology they provide. The users are presented as decision makers within the firm, transgressing four decision-episodes in an iterative process.

This research focuses on the first two episodes of the DEF; agenda formation and selection. In these, episodes users seek to match their 'fuzzy' image of the innovation with their own 
requirements. Problems are defined and solutions are generated. However, this does not necessarily occur sequentially. The process is seen as iterative, with many instances of problems chasing solutions (Swan \& Clark, 1992). The episodes of agenda formation and selection are crucial because here, there are many opportunities for users to redefine the innovation as presented by the supply side. These design decisions can have important implications for subsequent implementation. However, whilst much research has focused on implementation and usage of CAPM technology, there has been relatively little research on the preceding episodes.

\section{METHODOLOGY}

The research was carried out during the summer of $1994^{*}$. In order to establish comparability, the three companies were selected using the following criteria:

- Manufacturing profile.

- Establishment size.

- Approximate time period within which the decision making process occurred.

There would be inherent problems of comparability if the research did not acknowledge a requirement to compare similar manufacturing profiles. The contextual embedding of CAPM technology imposes a requirement to compare like with like. A company operating batch production techniques is not comparable to a company operating to a make-to order profile. Their CAPM requirements will be qualitatively different. The three companies selected were all characterised by a make-to-order profile.

It was also important to compare companies of similar size. For this research, large companies were selected with employee levels of between 1500 and 3000. Investment decisions in new technology and the management of change will be qualitatively different in a small to medium sized company when compared to a large company.

Interorganisational networks will inevitably change over time, in both composition and relative significance to the diffusion process. Chronologically, all three companies had embarked upon agenda formation and selection of CAPM technology during the late 1980's. They were also geographically proximate. It was assumed then, albeit to a limited degree, that interviewees' perceptions of networks would be relatively similar.

The main methodology used for the research was semi-structured interviews with personnel involved in the decision making process. Each company had set up a project team to consider the introduction of some form of CAPM technology. A total of 12 interviews were carried out with individuals who had formed part of these teams across the three companies. Interviews focused specifically on how the individual had developed an awareness of MRPII and the networks that informed decisions at that time. Whilst adoption was not the focus of the research, inevitably, interviewees also discussed outcomes of their attempts to implement MRPII.

Secondary sources of data, in the form of minutes of meetings and company reports, were also made available during the period of the research. These were used to support interviewees' perception's of the decision making process. Journals from three professional associations dating from 1984 to 1989 were also analysed. This analysis was used to establish what forms, and to what extent, CAPM technologies were being promoted over this time period. The three associations were:-

- BPICS (The British Production \& inventory Management Society).

- IMechE (The Institute of Mechanical Engineers)

- IEE (The Institute of Electrical Engineers - Manufacturing Division).

\footnotetext{
* The research was kindly funded by the Economic \& Social Research Council
} 
A comparison across three companies cannot be used to infer broader generalisations. It does however, allow the diffusion process to be contextualised. This is a necessary prerequisite, if a fuller understanding of the diffusion of MRPII technology is to be developed.

\section{RESULTS}

The findings are presented in Table 1.

\section{Table 1}

\begin{tabular}{|c|c|c|c|}
\hline & COMPANY A & COMPANY B & COMPANY C \\
\hline $\begin{array}{l}\text { Composition of the } \\
\text { Project Team }\end{array}$ & $\begin{array}{l}\text { - Special Projects } \\
\text { Mgr } \\
\text { (Engineering) } \\
\text { - Logistics } \\
\text { systems Mgr. }\end{array}$ & $\begin{array}{ll}\text { - } & \text { Team Leader } \\
& * \mathrm{C} \\
\text { - } & \text { Mgrl } \\
& \text { representatives: } \\
\text { 1. manf. systems } \\
\text { 2. prod control } \\
\text { 3. matl's mgmt } \\
\text { 4. manf } \\
\text { engineering }\end{array}$ & $\begin{array}{ll}\text { - } & \text { Mgrl. } \\
\text { representatives: } \\
\text { 1. Logistics } \\
\text { 2. Sales \& } \\
\text { Marketing } \\
\text { 3. Manf. Systems } \\
\text { 4. } \text { manf. } \\
\text { engineering } \\
\text { 5. operations } \\
\text { mgmt. } \\
\text { - Consultants *C } \\
\text { (Coopers \& } \\
\text { Lybrand) }\end{array}$ \\
\hline
\end{tabular}

\begin{tabular}{|c|c|c|c|}
\hline $\begin{array}{l}\text { Interorganisational } \\
\text { networks accessed } \\
\text { Professional } \\
\text { Associations }\end{array}$ & BPICS $* C$ & $\begin{array}{l}\text { IMechE *C } \\
\text { IEE } * \mathbf{C} \\
\text { BPICS } * \mathbf{C}\end{array}$ & BPICS *C \\
\hline $\begin{array}{l}\text { Academic } \\
\text { Institutions }\end{array}$ & $\begin{array}{l}\text { University of } \\
\text { Warwick MBA } * \mathbf{C}\end{array}$ & & \\
\hline Other Firms & $\begin{array}{l}\text { Reference sites } * \mathbf{C} \\
\text { Few }\end{array}$ & $\begin{array}{l}\text { Reference sites } * \mathbf{C} \\
\text { Few }\end{array}$ & $\begin{array}{l}\text { Visits arranged } \\
\text { through weak ties } \\
\text { Many }\end{array}$ \\
\hline Suppliers & $\begin{array}{l}\text { Oliver Wight } \\
\text { Consultants }\end{array}$ & $\begin{array}{l}\text { Oliver Wight } \\
\text { Consultants }\end{array}$ & $\begin{array}{l}\text { Oliver Wight } \\
\text { Consultants }\end{array}$ \\
\hline CAPM Solution & MRPII & MRPII & MRPII + JIT \\
\hline $\begin{array}{l}* * \text { Outcome ( level } \\
\text { of appropriation) }\end{array}$ & $\begin{array}{l}\text { Partial } \\
\text { implementation } \\
1-2\end{array}$ & $\begin{array}{l}\text { Failure } \\
1-1\end{array}$ & $\begin{array}{l}\text { Success } \\
1-4\end{array}$ \\
\hline
\end{tabular}


** Outcome - Levels of CAPM Integration ( from Waterlow \& Monniot, 1986).

\begin{tabular}{ll}
\hline 0 No CAPM & No CAPM or presently being installed \\
1 No integration & Several functions computerised but without regards to integration \\
2 Partial integration & Several functions linked via common files and coordinated controls \\
3 Full integration & All CAPM functions using common databases \\
$\begin{array}{c}\text { 4 Integration of } \\
\text { manf systems }\end{array}$ & CAPM systems designed in conjunction with material conversion \\
& handling, and quality systems against manufacturing strategy objectives.
\end{tabular}

Table 1 summarises the networks accessed during the decision making process .Antecedent context is not presented other than to state that all three companies had defined a requirement for some form of CAPM technology, in order to replace outdated, disparate systems or to manage increased demand. There was evidence of direct consultant involvement in many of the networks accessed by the project teams in all three companies. Considering the research findings for each company:-

The Logistics Systems manager in Company A first became aware of MRPII when he attended a BPICS seminar in 1985. At the time he was not a member of BPICS. He attended as a guest, and the seminar was free. Free seminars are always given by software vendors and consultants

The Special Projects manager in Company A became aware of MRPII whilst completing a part-time MBA at the University of Warwick. A course option was Manufacturing Planning \& Control Systems. An external academic and consultant William Berry, from the University of North Carolina lectured on this option. He is co-author of a book 'Manufacturing Planning \& Control systems' (Vollman \& Berry, 1985), which focuses solely on the use of MRPII technology. The book is dedicated to the memory of Oliver Wight; 'a pioneer in manufacturing planning and control'. The company founded by this individual - The Oliver Wight Organisation, is a major US consultancy specialising in the provision of education and training in MRPII concepts both in the US and Europe. During the 1980's, the Oliver Wight Organisation was heavily involved in promoting MRPII as best practise with respect to CAPM.

Before Company A Board gave final approval for the introduction of MRPII they asked Oliver Wight consultants to provide two reference site visits. These visits were arranged in order to see MRPII technology applied. Subsequently, the Board gave their approval for investment in MRPII.

In Company B there was consultant involvement in the project team as well as the networks accessed. Failure to introduce various technological initiatives previously, had demonstrated that there was a severe lack of integration and co-operation across functional boundaries. The Manufacturing Director looked to appoint a project team leader who was objective and could remain "above the politics of the company". A consultant known to Company B was appointed as project leader.

All of the team attended mandatory, in-house presentations given by an independent US consultant Hal Mather (Inc.), on the subject of manufacturing control. He was invited to speak in his capacity as a Fellow of the Institute of Mechanical Engineers (IMechE) with which snior members of Company B had links. MRPII as a distinct technology was the focus of the presentations. All of those interviewed in Company B spoke very positively about the knowledge provided by this consultant, reinforcing their comments with reference to his association with the IMechE. Hal Mather is also a Fellow in the Institute of Industrial Engineers (IEE). His book, 'Competitive Manufacturing' (1986), is also an American Production \& Inventory Control Society (APICS) publication. 
Two members of the team in Company B were also BPICS members. Hence, most of the team attended BPICS seminars where the concept of MRPII was discussed. These seminars were given by vendors and focused solely on the application of this technology. Those interviewed believed that these events were an opportunity to meet other users/potential users of MRPII which enhanced their understanding of the technology.

The project leader was aware that the Oliver Wight Organisation were a specialist MRPII consultancy from previous consultancy assignments. He recommended contacting the Oliver Wight organisation for further information regarding MRPII.

Reference site visits were also arranged in order to establish which software package would be most appropriate if MRPII were to be adopted. The team invited six vendors to tender. All six vendors provided reference sites both in the UK and the US. Following these visits, Board level approval was given to invest in software and an education and training package provided by the Oliver Wight Organisation.

Company $\mathrm{C}$ brought in a major firm of consultants to support the decision making process. The team was led by the Managing Director. The team had already developed a detailed business system specification. They were seeking a CAPM solution to support this. Management consultants were to be used to assess software vendor suitability and provide technical expertise considered lacking in the composition of the team.

The Logistics Director was a very active member of BPICS at the time. Through his active participation in branch meetings, seminars and conferences he had developed an in-depth understanding of the MRPII concept. This knowledge was disseminated to the rest of the team.

The major consultancy involved, having considered Company C's business requirements, advocated the adoption of MRPII technology. They arranged for the Oliver Wight Organisation to make a presentation to the Board. The presentation outlined what the technology consisted of and the organisational changes required to support the technology.

The team was aware that their manufacturing profile did not comfortably 'fit' the MRPII concept. Consequently they also actively sought out other companies with a similar profile and arranged factory visits. The purpose of these visits was to ascertain what technologies were being used to aid manufacturing control in organisations facing similar manufacturing problems. These visits were arranged through informal contacts individual team members had with members of other firms e.g. suppliers, competitors, ex-colleagues. Those interviewed indicated that these reference site visits led them to an awareness of other technologies such as JIT and OPT.

The team was conscious that the company's operations were not going to try and 'fit' MRPII technology. The Board was only prepared to invest in the appropriate CAPM solution for the predefined business requirements. The team recommended to the Board that MRPII be implemented in a limited capacity, in order to forecast, schedule, and communicate with the supplier base. A JIT Kanban system, in combination with in-house designed PC based systems, were advocated for detailed shop floor planning and control. These would interface with the MRPII system. In effect, as one team member stated; "we were going to put a shell around the factory and organise shop floor control ourselves ".

Company $\mathrm{C}$ used the Oliver Wight Organisation to initiate education and training. This was not successful. Senior team members who attended the Oliver Wight courses were aware that they were being offered," a single point solution". Company $\mathrm{C}$ were sufficiently confident of their 'pragmatic' approach to the development of their CAPM systems, they rejected much of the courses' content. Hence, Company $\mathrm{C}$ used the Oliver Wight Organisation sparingly for education and training. In-house training courses were developed which encompassed Company C's unique approach to the development of their CAPM systems. 


\section{DISCUSSION}

In all three companies, those interviewed were both aware and wary of the rhetoric and bias of software vendors and management consultants. The supplier network was acknowledged to have a vested interest in promoting the diffusion of specific CAPM technologies. Hence, each company set up a multi-disciplined project team to actively seek out other knowledge domains, that could provide less biased information. On the basis of this knowledge being made available, a decision based on rational / efficient choice could then be taken. Whilst all three companies followed a similar decision making process, the outcome was different in each case.

Company A had limited success. MRPII was implemented partially with some integration across functions. Company A had used an existing software package, and this was considered to inhibit full implementation. Company B experienced severe problems. There was a lack of support for the introduction of MRPII across certain functions. The high levels of data accuracy, a prerequisite to successful implementation, were not achieved. Ultimately the implementation failed and MRPII was not adopted. Company $C$ was most successful and achieved Class 'A" status as specified by the Oliver Wight certification system (Wight, 1977). Class ' $A$ ' indicates that MRPII has been fully implemented, supporting all functions and is integrated with company business strategy.

The research found that there was significant consultant involvement in the majority of interorganisational networks accessed. It was only the network of weak ties accessed by company $\mathrm{C}$ that had not been interpenetrated by consultants. Previous research has shown significant consultant involvement in the associations whose members were most closely involved in operations management in the UK and US (BPICS and APICS respectively). This current research supports these findings and extends the scope of professional associations promoting MRPII, to include the IMechE and the IEE. This was highlighted by the involvement of the consultant, Hal Mather, in all three professional associations. His involvement typifies the use made of professional associations by consultants, as an important channel for the diffusion of knowledge about their products and technologies. This consultant activity can also be identified in the analysis of the professional associations' journals. A detailed analysis of the content of these professional associations' journals over the period between 1984 and 1989 found that all three association journals were promoting MRPII to a far greater extent than JIT in the period up to 1989. For example, in that period, the IEE journal contained 43 articles about MRPII, compared to 13 articles about JIT. The role played by consultants in professional associations is also illustrated by their level of activity within the associations. For example, consultant activity in BPICS during 1994 is shown below in Table 2.

Table 2

\begin{tabular}{lllll}
\hline Membership & \% of Total & Conference & Conference & Journal Article \\
Category & Membership & Presentation & Participation & Contribution
\end{tabular}

\begin{tabular}{lllll} 
Practitioner & 70 & 60 & 26 & 37 \\
$\begin{array}{c}\text { Consultants/ } \\
\text { Vendors }\end{array}$ & 23 & 31 & 55 & 76 \\
\hline
\end{tabular}


Whilst consultants actually represent a minority of the BPICS membership they are more involved in the activities of the association as both participants and more especially as presenters of 'new ideas'.

Perceptions of consultants and the knowledge they provide, appears to be distorted positively in their favour through their active involvement in professional associations. Involvement in the professional association network conferred a degree of legitimacy on the consultancy role. The information provided by consultants through their links within the professional association network is perceived to be 'neutral'. During interviews, comments were made about Hal Mather such as "he speaks a lot of sense" and "he understands the real world". These comments were then supported by reference to his position as a Fellow of the IMechE, implying both status and expertise.

Potential adopters of technology may perceive the academic network to be a 'neutral' source of information and assume that the knowledge provided is relatively untainted by vested interests. However, the research highlighted the involvement of consultants in the academic network too. Presented with subject matter firmly grounded in the 'real world' of manufacturing, there is an opportunity for 'experts', other than academics, to disseminate knowledge and expertise within this network. Consultants are in a position whereby they can commodify this knowledge (Zucker, 1991) and hence, the 'neutrality' of the knowledge is questionable. It would not be in the interests of consultants to impart information / knowledge that does not promote their own economic self interest. This research found that the knowledge acquired through the academic network was selective. MRPII technology was presented as the optimal production planning and control tool. Little reference was made to JIT and no reference was made to OPT.

The reference site network is a more obvious example of vendor/consultant involvement. Only those sites that were able to present a positive, unproblematic perception of the technology were selected for factory visits by both the software vendors and consultants. It would not be in the interests of vendors and consultants to organise reference site visits where the technology had failed!

It is important to recognise that it was only the interorganisational network of weak informal ties (used by Company C), which was able to provide information/knowledge regarding other CAPM technologies. The team at Company $\mathrm{C}$ had developed a clear business system specification, prior to considering the technology required to support it. The team recognised that sources of information made available through a range of networks, had only helped them to develop an understanding of MRPII. They were aware that this was not sufficient to satisfy their business requirements. Hence, the team at Company $\mathrm{C}$ were forced to consider other information sources. Through the use of weak ties, members accessed less formal networks and developed an understanding of all of CAPM variants.

This network of weak ties operated on an informal basis. Relationships had developed and the exchange of knowledge and expertise occurred, in an environment of trust and cooperation. This is in contrast to the more formal knowledge diffusion process, where the exchange of information and knowledge is selective and governed by the economic selfinterest of consultants.

Ultimately, the networking activity that occurred across each of the case companies did not provide the 'neutral' information being sought. Other networks accessed actually served to reinforce the pro-innovation bias of vendors/consultants. Consultants, using the guise of professional status, effectively camouflaged themselves within these other networks and were able to disseminate knowledge and expertise which was both selective and in their own interest to impart. This aspect of the diffusion process is not captured either by Rogers or by the DEF. 
This analysis suggests an update to the DEF (Figure 3) to include these other networks and to show the inter-relationships between them. It also highlights the dynamics of the relationship between the different interorganisational networks and potential adopters in terms of boundary spanning activity. These interrelationships would be expected to vary across nations. The linkages established will depend on the societal and institutional context in which organisations are embedded. For example, professional associations may play a more significant role in some countries than others (Child et al, 1983).

Figure 3: Update to the DEF

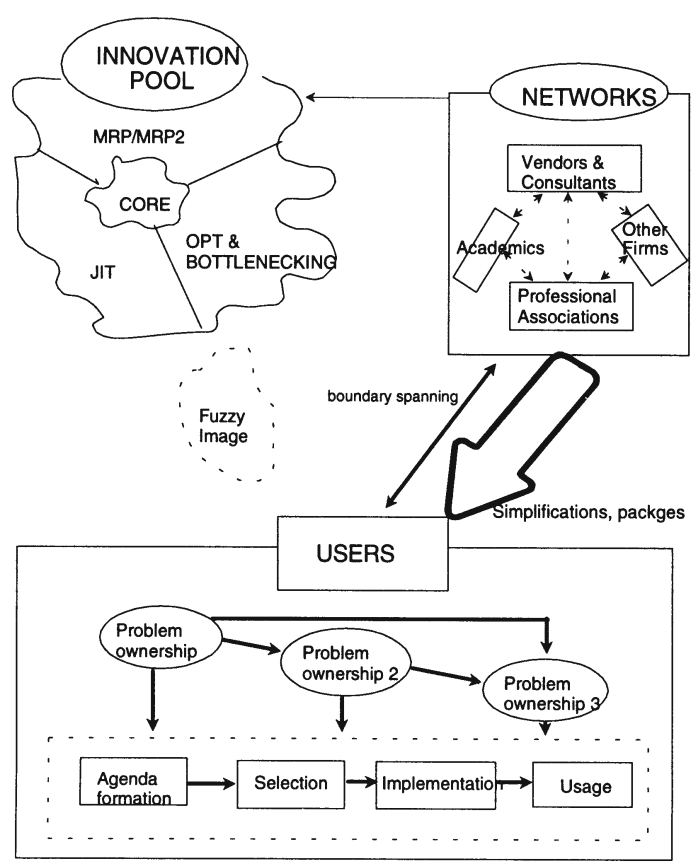

This research has also provided a useful example of institutionalised isomorphic processes operating (DiMaggio \& Powell, 1983). DiMaggio \& Powell's hypothesis recognises that within certain developed industrial sectors, there is a tendency for firms to develop homogeneously rather than remaining differentiated. This is due largely to the influence of powerful forces such as competition, the state and professions. Institutionalised isomorphism is recognised as aiding the diffusion of specific technologies in that as an innovation spreads, a threshold is reached (in terms of adopters) beyond which adoption provides legitimacy rather than improve performance (DiMaggio \& Powell, 1983). This research provides insight into the way in which this can occur. Individuals in all three companies visited reference sites and attended professional association seminars, which promoted the concept of MRPII, effectively legitimising the use of MRPII, to the exclusion of other technologies.

This theme is also reflected by Abrahamson (1991) who suggests that within certain organisational groups the adoption of technological innovation is governed more by a fashion perspective, rather than the efficient-choice perspective which dominates the diffusion 
literature. Efficient choice assumes that organisations act rationally, independently and with certainty, regarding both their own strategic goals and the efficiency of the technology. The fashion perspective suggests that organisations within a group are influenced by fashion setting organisations outside of the group (management consultants, professional associations), which subsequently leads to the diffusion of certain technologies at the expense of others. This may occur even when, (as in these cases), the organisations believe they are acting, following a process of rational decision making. These interrelated concepts suggest that organisations which become active in interorganisational networks may be prone to the effects of institutionalised isomorphism. Fashions, set in many cases by vendors and consultants, subsequently enable the diffusion of certain technologies whilst constraining the diffusion of others. Thus, companies may adopt technologies which are not necessarily appropriate, influenced by the knowledge domains accessed during the decision making process.

\section{CONCLUSION}

This research found that during the late 1980 's, certain companies within the UK automotive sector were involved in interorganisational networks that promoted the diffusion of certain technologies at the expense of other variants. Using CAPM technology as an example, the research found, in keeping with others, that a variety of networks reinforced and shaped availability of MRPII ( Newell \& Clark, 1990, Swan \& Newell, 1995). Other CAPM technologies existed at this time e.g. JIT and OPT, yet were not actively promoted by these networks. The activity of consultants specialising in MRPII, within these other networks may be an explanatory factor for this. Potential adopters of CAPM technology experienced difficulties in gaining access to networks which did not shape availability of CAPM technology at this time. Potential adopters of technology assumed (perhaps wrongly) that outside of the vendor/supplier network, knowledge domains existed that could provide a source of 'neutral' information. However, it is perhaps questionable that this could ever be the case. Consultant activity in these interorganisational networks, whilst legitimate, is going to be driven by an interest in developing new business and in encouraging firms to adopt new technologies.

This research suggests that diffusion rates of CAPM technologies cannot necessarily be predicted by adopting the efficient-choice perspective, which dominates the innovation diffusion literature (Rogers, 1971). MRPII technology was actively promoted by a range of interorganisational networks to the exclusion of other variants of CAPM. Thus, this research has provided an explanation (not necessarily complete), for the successful diffusion of MRPII into organisations, in spite of the high failure rates associated with appropriation of this technology.

\section{REFERENCES}

Alter, C. and Hage, J. (1993).. Organisations Working Together. Sage, Newbury Park, CA: Child, J., Fores, M., Glover, I. and Lawrence, P. (1983) A Price to Pay? Professionalism and Work Organisation in Britain and West Germany. Sociology. 17, 63-78.

Clark, P. A. (1987) Anglo-American Innovation. DeGruyter, New York

Clark, P., Bennett, D., Burcher, P., Newell, S., Swan, J., and Sharifi, S. (1992). The DecisionEpisode Framework and Computer-Aided Production Management (CAPM). International Studies of Management \& Organisation. 22, 69-80.

Clark, P. A. and Staunton N. (1989). Innovation in Technology and Organisation. Routledge, London

DiMaggio, P. and Powell, W. (1983). The iron Cage Revisited: Institutional Isomorphism and Collective Rationality in Organisational Fields. American Sociological Review. 48, 147-160. 
Fleck, J. (1993). Configurations: Crystallizing Contingency. The International Journal of Human Factors in Manufacturing. 3, 15-36.

Granovetter M. S. (1973). The Strength of Weak Ties. American Journal of Sociology. 78, $1360-1380$.

Krupp, J. A. G. (1984). Why MRP Systems Fail: Traps to Avoid. Production \& Inventory Management 27, 49-53.

Mather, H. (1986). Competitive Manufacturing. Prentice-Hall, New Jersey.

N.E.D.O. (1984). Computers in Production Control.

Newell, S and Clark, P. (1990). The Importance of Extra-organisational networks in the Diffusion and Appropriation of new technologies. Knowledge: Creation, Diffusion, Utilisation. 12, 199-212.

Newell, S., Swan, J. and Clark, P (1993). The Importance of User Design in the Adoption of New Information Technologies: The Example of PICS. International Journal of Operations \& Production Management. 13, 4-21.

Pinch, T. P. and Bijker, W.E. (1989) The Social Construction of Facts and Artifacts: Or How the Sociology of Science and the Sociology of Technology Might Benefit Each Other, in The Social Construction of Technological Systems (Eds.Bijker, Hughes and Pinch), MIT Press, Cambridge, Massachusettes:

Rogers, E. M. (1962, 1983 3rd Ed.). Diffusion of Innovations. Free Press, New York. Rogers, E. M. (1971). Communication of Innovation. Free Press, New York.

Swan J. and Newell, S. (1995). The Role of Professional Associations in Technology Diffusion. Organisation Studies, 16 (In press).

Tushman, M. and Scanlan, T. (1981). Boundary Spanning Individuals: Their Role in Information Transfer and their Antecedents. Academy of Management Journal.24, 289-305. Vollman, A. and Berry, W. (1985). Manufacturing Control. Dow Jones-Irwin, Illinios Waterlow, J. G. and Monniot, J.P. (1986). A study of the state of the art in CAPM in UK Industry, ACME Directorate, Science \& Engineering Research Council, 1986.

Wight, O. (1984). Manufacturing Resource Planning: MRPII. Oliver Wight Publications, Vermont.

Wilson, F., Desmond, J., \& Roberts, H. (1994). 'Success and Failure of MRPII implementation'. British Journal of Management. 5:221-240

Zucker, L (1991). Markets for bureaucratic authority and control: Information quality in professions and services. Sociology of Organisations. 8,157-190.

\section{BIBLIOGRAPHY}

Maxine Robertson is a research fellow currently working with Dr Jacky Swan and Dr Sue Newell on a three year research project funded by the ESRC. The reseach project is a five country comparative study, focusing on the role of professional associations in the diffusion of technological innovation. Jacky Swan and Sue Newell are both psychologists and lecture in Organisational Behaviour at the University of Warwick Business school. 